\title{
Physical methods of microalgal biomass pretreatment**
}

\author{
Agata Piasecka*, Izabela Krzemińska, and Jerzy Tys \\ Institute of Agrophysics, Polish Academy of Sciences, Doświadczalna 4, 20-290 Lublin, Poland \\ Received November 11, 2013; accepted April 27, 2014
}

\begin{abstract}
A b s t r a c t. The prospect of depletion of natural energy resources on the Earth forces researchers to seek and explore new and alternative energy sources. Biomass is a composite resource that can be used in many ways leading to diversity of products. Therefore, microalgal biomass offers great potential. The main aim of this study is to find the best physical method of microalgal biomass pretreatment that guarantees efficient lipid extraction. These studies identifies biochemical composition of microalgal biomass as source for biodisel production. The influence of drying at different temperatures and lyophilization was investigated. In addition, wet and untreated biomass was examined. Cell disruption (sonication and microwave) techniques were used to improve lipid extraction from wet biomass. Additionally, two different extraction methods were carried out to select the best method of crude oil extraction. The results of this study show that wet biomass after sonication is the most suitable for extraction. The fatty acid composition of microalgal biomass includes linoleic acid (C18:2), palmitic acid (C16:0), oleic acid (C18:1), linolenic acid (C18:3), and stearic acid (C18:0), which play a key role in biodiesel production.
\end{abstract}

K e y w ord s: biomass, sonication, microwave, lipid content, microalgae

\section{INTRODUCTION}

Population growth and civilization development is inextricably linked to the rate of exploration of fossil fuels. Furthermore, world demand for energy is still increasing. Consumption and use of energy causes emission of significant amounts of $\mathrm{CO}_{2}$ and climate changes. However, at the same time there is a clear move away from oil and coal towards renewable energy sources (IEA, 2012).

Biomass is a renewable energy source regarded as a source with the greatest potential to satisfy all the energy needs. The most important biomass sources are wood and

\footnotetext{
*Corresponding author e-mail: a.palcowska@ipan.lublin.pl

**This work was partly financed by the Ministry of Science and Higher Education, Poland, grant No. N N313 705940, 2011-2014.
}

wood remains, energy crops, agricultural crops and residues, food waste, animal waste, municipal solid waste, aquatic plants and among them macroalgae and microalgae (Demirbas et al., 2009).

Microalgal biomass has been recognized as a feedstock and a good source for lipid-based biofuel production. In addition, it is one of the few real opportunities to meet energy needs (Ahmad et al., 2011).

Microalgae are a group of microorganisms with a relatively simple structure. These are mostly phototrophic organisms occurring in very different habitats. Microalgae are a very diverse group of organisms and their heterogeneity is conditioned by a number of characteristics, including the place of occurrence, the level of organization of the cell, the type of pigments, size, or metabolic pathways. Microalgae have the ability to synthesize and accumulate triacylglycerols under stress conditions. Triacylglycerols (TAGs) are present in the cell in the form of storage lipids (Barsanti and Gualtieri, 2006; Qiang et al., 2008). In particular, triacylglycerols can be utilized as a source for biodiesel production (Fu et al., 2010).

Knowledge about the physical properties and structure of lipids can facilitate separation of lipids compounds from biological materials. Lipids are a heterogeneous group of biological substances mainly consisting of non-polar (neutral) and polar molecules. The polarity of a molecule is determined by the presence of fatty acids. The charge of neutral lipids mainly in the form of triacylglycerols determines their structure, namely they are composed of a fatty acid molecule whose carboxylate end is bonded with uncharged glycerol (Kates, 1986a). However, triacylglycerols are regarded as less polar neutral lipids because they can be covalently bound to carbohydrates and proteins (Shahidi and Wanasundara, 2002).

C 2014 Institute of Agrophysics, Polish Academy of Sciences 
Insolubility in water is a main property that allows isolation of lipids. Furthermore, solubility of lipids in organic solvents facilitates separation of lipids but the use of one universal solvent for lipid extraction in not possible. The nature of the sample and the type of lipids in the material determines the extraction method and solvent used (Shahidi and Wanasundara, 2002). Using the principles of 'like dissolves like' predominantly, non-polar organic solvents such as chloroform and hexane are used. Additionally, polar solvents (such as methanol) improve extraction of some complexforming neutral lipids; thus, a mixture of non-polar/polar organic solvents is appropriate for lipid extraction from microalgal biomass and this practice is very common (Halim et al., 2012a; Kates, 1986b; Robles Medina et al., 1998).

A large number of lipid extraction methods used for microalgal biomass have been described. The most important fact is that microalgae are single cell microorganisms having an individual cell wall (Ryckebosch et al., 2012). Furthermore, microalgae often have unusual levels of lipids or their substitutes with a unique structure and valuable properties, but functionally they are similar to lipids found in other plants (Goschina and Harwood, 2006; Guy and Thompson, 1996). Therefore, the choice of a single universal method of extraction for all species is difficult.

The method of Bligh and Dyer (1959) with chloroform - methanol in the ratio of 1:2 is often used for extraction of total lipids from microalgae. Nevertheless, Iverson et al. (2001) reported that unmodified Bligh and Dyer method was not appropriate for microalgal biomass. They mentioned that all modifications to the procedures and solvent/ sample ratios should be described because evaluation and comparison of results is easier. Hexane is also one of the most desirable hydrocarbon solvents designed for triacylglycerol extraction (Christie, 1982).

Pretreatment of biomass and sample preparation is an important step. In a standard 2-step laboratory scale pretreatment pathway, the concentrate is dried and then milled into powder (Halim et al., 2012a). However, there is a hypothesis that drying biomass is not a necessary kind of pretreatment. Many valuable compounds have been extracted from wet biomass of microorganisms (fungi and bacteria) (Kates, 1986b). Studies on wet lipid extraction have been very scarce. Drying biomass especially at elevated temperatures is undesirable due to generation of bonds between lipids and other compounds hindering solvent extraction (Pomeranz and Meloan, 1994). Furthermore, drying and dewatering microalgal biomass are processes which result in incredible energy consumption and have a limiting effect on commercial scale production of biofuel from microalgal biomass (Sathish and Sims, 2012; Tanzi et al., 2013). For the efficiency of the extraction process, it is very important that the cell structure has been completely disintegrated. Lipid yields increase with the degree of cell disruption, as lipids are discharged from the cellular structures outside the cell.
Mechanical, chemical, and enzymatic methods are most widely used for cell disintegration in microorganism biomass. Ultrasonication and microwave are distinguished among them. It is important that most methods used to disrupt cells demand a small amount of water in algal biomass for successful cell disintegration (Halim et al., 2012a).

In this investigation, algal oil extraction from Chlorella protothecoides was studied. This microalga has a high content of total lipids (50.3-57.8\%) under heterotrophic conditions and the properties of biodiesel from Chlorella comply with the US standard for biodiesel. Furthermore, these properties are comparable to those of conventional diesel (Xiong et al., 2008).

The aim of this study was to find an extraction technique that guarantees efficient algal oil extraction. The effect of biomass pretreatment, the cell disruption methods, and the type of solvents on algal lipid yield were studied. Moreover, the effect of these parameters on the fatty acid methyl esters (FAME) content was investigated because FAMEs play a key role in biodiesel production.

\section{MATERIALS AND METHODS}

The axenic culture of Chlorella protothecoides (No. 211-7a) was obtained from The SAG Culture Collection of Algae in Götteningen, Germany. Polytoma medium was used for Chlorella protothecoides culturing. The composition of the Polytoma medium is shown in Table 1. The microalgal strain was inoculated from a $2 \%$ agar plate into $50 \mathrm{ml}$ Erlenmeyer flasks with Polytoma medium and precultured. When the cultures reached the exponential growth phase, they were transferred to $500 \mathrm{ml}$ Erlenmeyer flasks with fresh Polytoma medium. The cultures were grown at $26^{\circ} \mathrm{C}$ with shaking without aeration to keep them sterile. The Chlorella prototecoides cultures were illuminated at a $16 \mathrm{~h}$ light/ $8 \mathrm{~h}$ dark cycle with light intensity of $100 \mu \mathrm{mol}$ photons $\mathrm{m}^{-2} \mathrm{~s}^{-1}$.

The photoheterotrophic culture in $500 \mathrm{ml}$ Erlenmeyer flasks was used to inoculate photobioreactors. First, a calibration curve, which showed the relationship between the optical density and the biomass concentration, was prepared. A series of tenfold dilution of the cell suspension was made and the optical density $\left(O D_{650}\right)$ was measured. The biomass concentration was estimated by dry mass determination. The cell suspension ( $1 \mathrm{ml})$ was filtered through

T a b l e 1. Composition of Polytoma medium

\begin{tabular}{lcc}
\hline Composition & $\begin{array}{c}\text { Stock solution } \\
\text { g } 100 \mathrm{ml}^{-1}\end{array}$ & $\begin{array}{c}\text { Nutrient solution } \\
\mathrm{ml}\end{array}$ \\
\hline Yeast extract & 10 & 10 \\
Bacto-tryptone & 10 & 10 \\
Soil extract & - & 30 \\
De-ionized water & - & 950 \\
\hline
\end{tabular}


a Whatman glass-fiber filter, dried at $90^{\circ} \mathrm{C}$ for $24 \mathrm{~h}$ (Venticell VC 111 laboratory dryer), and weighed. The $O D_{650}$ values were converted to dry mass $(D M)$ values:

$$
D M=267.94 O D_{650}+0.145\left(\mathrm{R}^{2}=0.999\right) .
$$

The average initial biomass concentration $0.03 \mathrm{~g} \mathrm{l}^{-1}$ was used to inoculate 3-1 photobioreactors (BIOSTAT PBR 2S, Sartorius Stedim Biotech). A large volume of microalgal biomass was obtained in the large-scale culture system. Chlorella protothecoides was grown in four photobioreactors on Polytoma medium at $26^{\circ} \mathrm{C}$ under illumination ( $16 \mathrm{~h} \mathrm{light} / 8 \mathrm{~h}$ dark cycle, $100 \mu \mathrm{mol}$ photons $\left.\mathrm{m}^{-2} \mathrm{~s}^{-1}\right)$. The cultures of microalgae were harvested by centrifugation at $14025 \mathrm{x} \mathrm{g}$ for $15 \mathrm{~min}$ (Rotanta $460 \mathrm{RS}$ centrifuge) after 12 days of cultivation. The cell biomass was washed twice with de-ionized water after centrifugation to remove medium residues.

Growth in the four photobioreactors was monitored daily by measuring optical density at $650 \mathrm{~nm}$. Growth parameters (specific growth rate, biomass doubling time, and biomass productivity) were determined based on the optical density measurement. Biomass productivity per day was expressed in $D M \mathrm{~g} \mathrm{l}^{-1}$ day $^{-1}$. The specific growth rate $(\mu)$ and biomass doubling time $\left(T_{d}\right)$ were calculated using the following formulas (Krzemińska et al., 2014; Yadavalli et al., 2010):

$$
\mu=\ln (N 2 / N 1) /(T 2-T 1),
$$

where: $\mu$ is specific growth rate $\left(\right.$ day $\left.^{-1}\right), N 1$ is the initial and $N 2$ is the final optical density measured at $650 \mathrm{~nm}, T 1$ is the initial and $T 2$ is the final time of cultivation.

$$
T_{d}=(\ln 2 \mu) 24
$$

where: $\mathrm{T}_{d}$ is biomass doubling time $(\mathrm{h})$.

The influence of two most popular types of pretreatment was investigated. In addition, rarely used wet biomass was analysed. Microalgal biomass was lyophilized (Labconco FreeZone 2.5 , freeze dryer) and dried at 40,60 , and $90^{\circ} \mathrm{C}$ in a laboratory dryer to constant mass and until the moisture content was reduced to $0 \%$ (moisture analyzer HG63). After drying and lyophilisation, the dry biomass was pulverized in a mortar to reduce the particle size. The microalgal biomass was subjected to two methods of lipid extraction, ie. a modified Bligh and Dyer method (1959) with chloroform: methanol and the method with n-hexane: methanol.

The modified Bligh and Dyer procedure consisted of the following steps:

- $1.25 \mathrm{ml}$ of chloroform and $2.5 \mathrm{ml}$ of methanol $(1: 2 \mathrm{v} / \mathrm{v})$ were added to each $100 \mathrm{mg}$ of the dried, powdered biomass;

- the samples were shaken on a shaker for 15-20 min;

$-1.25 \mathrm{ml}$ of chloroform was added to the samples and they were shaken on a vortex, which was followed by addition of $1.25 \mathrm{ml}$ of water, and the samples were shaken again;
- the samples were centrifuged for $10 \mathrm{~min}$ at $600 \mathrm{x} g$ to obtain two layers;

- the lower layer of each sample was transferred to roundbottomed flasks;

- the solvents were removed with a vacuum evaporator.

The n-hexane and methanol procedure consisted of the following steps:

$-3.75 \mathrm{ml}$ of hexane and $2.5 \mathrm{ml}$ of methanol $(3: 2 \mathrm{v} / \mathrm{v})$ were added to each $100 \mathrm{mg}$ of the dried, powdered biomass;

- the samples were shaken on a shaker for 15-20 min;

$-1.25 \mathrm{ml}$ hexane was added to the samples and they were shaken on a vortex; next, $1.25 \mathrm{ml}$ of water was added and the samples were shaken again;

- the samples were centrifuged for $10 \mathrm{~min}$ at $600 \mathrm{x} g$ to obtain two layers;

- the higher layer of each sample was transferred to roundbottomed flasks;

- the solvents were removed with a vacuum evaporator.

Wet biomass (equal to $100 \mathrm{mg}$ of dry biomass) was also used in the two lipid extraction methods using the same procedures.

All extractions were performed in triplicate. Total lipid yield was measured gravimetrically.

The following cell disruption methods, applied before solvent extractions, were tested to achieve more efficient lipid extraction. Sonication was performed using a Sonics vibra cell 500 sonicator. The samples were treated by ultrasonic waves for $90 \mathrm{~s}$ (power $500 \mathrm{~W}$, frequency $-20 \mathrm{kHz}$ and amplitude $-50 \%$ ). The samples were placed in an ice bath to protect against overheating. Microwave pretreatment was performed in the microwave oven for the same period of time (power $800 \mathrm{~W}$, frequency - $2450 \mathrm{MHz}$ ).

After extraction, crude oil was collected. $1 \mathrm{ml}$ of crude oil suspended in hexane was transferred to glass ampoules, mixed with $6 \mathrm{ml}$ of $0.5 \mathrm{M} \mathrm{KOH}$ in methanol, and hydrolyzed at $80^{\circ} \mathrm{C}$ for $1 \mathrm{~h}$. Next, $6 \mathrm{ml}$ of $10 \% \mathrm{BF}_{3}$ in methanol was added and shaken on a vortex. Esterification was performed at $100^{\circ} \mathrm{C}$ for $20 \mathrm{~min}$. After cooling at room temperature, $1 \mathrm{ml}$ of HPLC grade hexane and $10 \mathrm{ml}$ of saturated $\mathrm{NaCl}$ solution was added and vortexed again. The FAMEs formed during esterification were accumulated in the hexane layer.

The samples were analyzed on a Trace GC Ultra with ITQ 1100 using a $105 \mathrm{~m}$ Rtx-2330 column with I.D. $0.25 \mathrm{~mm}$ and $0.25 \mu \mathrm{m}$ film thickness. Helium was used as a carrier gas with $1 \mathrm{ml} \mathrm{min}^{-1}$ constant flow compensation, the split ratio was $20: 1$, injection temperature of $250^{\circ} \mathrm{C}$, and the temperature range from 60 to $250^{\circ} \mathrm{C}$ at $5^{\circ} \mathrm{C} \mathrm{min}{ }^{-1}$. Calculations were based on previous analysis of the standard mixture.

The statistical analyses were carried out using STATISTICA 10 (StatSoft Inc., USA). Two-factor (solvents and pretreament) analysis of variance (ANOVA) was used to test the effect of the type of extraction and the different modes of biomass preparation on the total lipid 
content and fatty acid methyl esters (C16:0, C18:0, C18:1, $\mathrm{C} 18: 2, \mathrm{C} 18: 3)$ content, $\mathrm{p}$-values below 0.05 were considered significant. Each measurement has at least three replicates; data are expressed as means $\pm \mathrm{SD}$.

\section{RESULTS AND DISCUSSION}

Recent publications have reported that photoheterotrophic growth conditions resulted in the highest biomass productivity. According to Isleten-Hosoglu et al. (2013), green microalgae Ettlia texensis achieved a three-fold greater biomass yield in photoheterotrophic culture than in an autotrophic one. Furthermore, one of the main components enhancing biomass productivity is yeast extract. Therefore, in this study Chlorella protothecoides was grown photoheterotrophically on Polytoma medium. Culturing under these conditions ensured the highest biomass productivity. Based on earlier studies, optimal growth conditions for the Chlorella protothecoides species were selected. The growth parameters are shown in Table 2. The dynamics of the specific growth rate during the culture is shown in Fig. 1. The correlation between optical density $\left(O D_{650}\right)$ and dry mass was used to make a growth curve (Fig. 2).

In this study, the influence of the extraction method and the effect of drying temperature and biomass preparation on the lipid content were examined. The results are shown in Table 3 . The extracted total lipid yield was highly dependent on the solvent. The type of solvent used in lipid extraction had a significant effect on the lipid yield $(\mathrm{p}<0.05)$. Lipids from dried, lyophilized, and non-pretreated microalgal biomass were extracted using two solvent combinations. The highest lipid extraction yield was at chloroform: methanol $(1: 2 \mathrm{v} / \mathrm{v})$. These results might be due to the more polar nature of the mixture consisting of chloroform and methanol, compared with hexane and methanol. The hexane: methanol (3:2 $\mathrm{v} / \mathrm{v}$ ) method yielded a smaller amount of crude oil. Widjaja et al. (2009) reported that hexane used as a solvent, compared with the chloroform:methanol mixture resulted in poor yield.

Triacylglycerols are deposited in lipid bodies located in the cytoplasm of algal cells (Qiang et al., 2008). During lipid extraction, non-polar solvents interact with neutral lipids in the cytoplasm through van der Waals forces. Then, the organic solvent-lipid complexes diffuse out of the cell. The situation is slightly different when neutral lipids form a complex with polar lipids. These complexes are strongly linked to proteins by hydrogen bonds. These connections only can be disrupted with polar solvents. The formation of complexes enforces the use of a mixture of non-polar/polar solvents (Halim et al., 2012a). TAGs classified as less polar neutral lipids should be extracted into less polar solvents such as chloroform because they may be extracted incompletely with non-polar solvents due to non-availability of an essential part of triacylglycerols to the non-polar solvents. However, extraction with the use of less polar solvents (chloroform)
T a b l e 2. Summary of Chlorella protothecoides growth parameters under photoheterotrophic conditions

\begin{tabular}{lc}
\hline Growth parameter & Value \\
\hline Specific growth rate $(0-4$ days $)\left(\right.$ day $\left.^{-1}\right)$ & $0.838 \pm 0.0300$ \\
Specific growth rate per hour $\left(\mathrm{h}^{-1}\right)$ & $0.009 \pm 0.0003$ \\
Biomass doubling time $(\mathrm{h})$ & $19.860 \pm 0.7000$ \\
Biomass productivity $\left(\mathrm{g} \mathrm{l}^{-1}\right.$ day $\left.^{-1}\right)$ & $0.079 \pm 0.0070$ \\
\hline
\end{tabular}

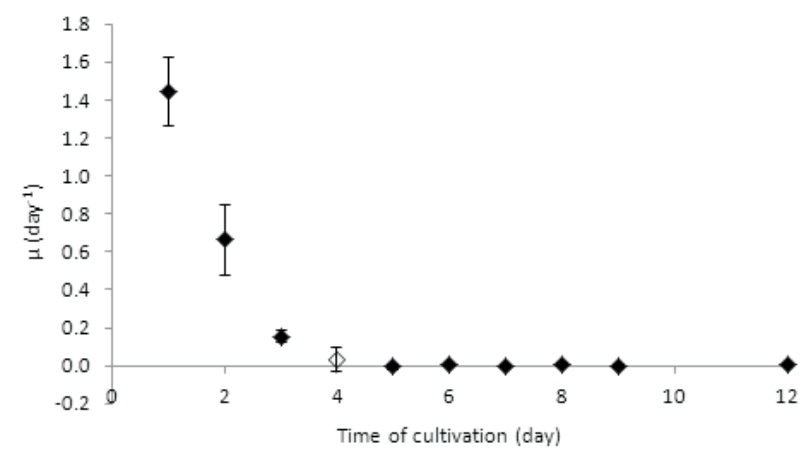

Fig. 1. Dynamics of the specific growth rate during the cultivation. Empty dot means the end of the exponential growth phase (fourth day of cultivation).

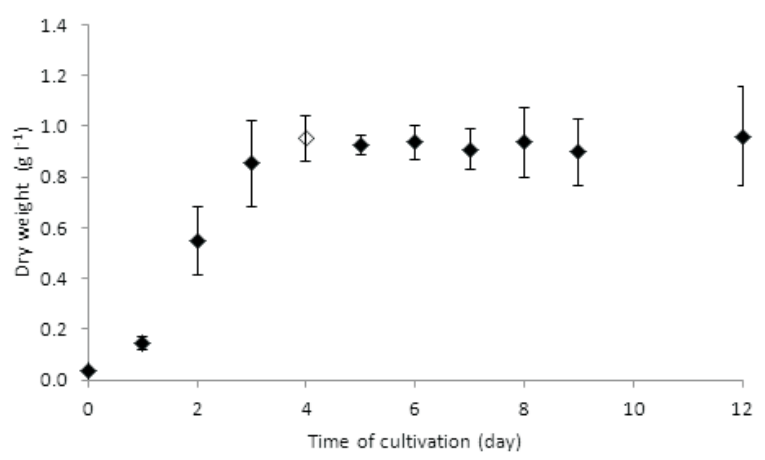

Fig. 2. Growth curve. During the cultivation, two phases (0-4 and 4-12 days) were observed. Empty dot means the end of the exponential growth phase (fourth day of cultivation).

results in the presence of such impurities as vitamins or dyes in the extract. In turn, hexane has higher selectivity towards the neutral lipid fraction and has low compatibility towards contamination (Shahidi and Wanasundara, 2002).

The highest crude oil content was observed in wet, thermally non-pretreated biomass during the chloroform: methanol extraction. In extraction of wet biomass, chloroform: methanol allowed more efficient extraction than non-polar hexane. 
T a b l e 3. Comparison of the lipid content under different methods of pretreatment of Chlorella protothecoides biomass

\begin{tabular}{|c|c|c|c|c|c|}
\hline \multirow{3}{*}{ Type of extraction } & \multicolumn{5}{|c|}{ Lipid content $(\% \mathrm{w} / \mathrm{w})$} \\
\hline & \multirow{2}{*}{$\begin{array}{c}\text { Lyophilized } \\
\text { biomass }\end{array}$} & \multicolumn{3}{|c|}{ Drying temperature $\left({ }^{\circ} \mathrm{C}\right)$} & \multirow{2}{*}{ Wet biomass } \\
\hline & & 40 & 60 & 90 & \\
\hline Hexane: methanol & $1.69 \pm 0.19$ & $4.18 \pm 2.59$ & $1.82 \pm 0.90$ & $1.06 \pm 0.40$ & $3.94 \pm 1.19$ \\
\hline Chloroform: methanol & $7.71 \pm 0.15$ & $6.25 \pm 0.64$ & $6.74 \pm 1.08$ & $6.70 \pm 0.64$ & $9.34 \pm 1.66$ \\
\hline
\end{tabular}

This emphasises the fact that the unmodified Bligh and Dyer method was designed for wet samples (Bligh and Dyer, 1959). According to Chun-Zhao et al. (2013), high amounts of water in samples blocked non-polar hexane penetration and resulted in low algal oil recovery. It was observed in the extraction using a mixture of the chloroform: methanol solvent that the lyophilized sample allowed efficient lipid extraction from microalgal biomass. This pretreatment method increased the availability of the sample. This method is also considered as a method for cell disintegration. Kachel-Jakubowska and Szpryngiel (2008) reported in their investigation, that drying is a very important step in post-harvesting, as it has a key role in changing the chemical composition of rapeseed. It is significant to define the correct drying temperature and eliminate its negative impact on the compositional quality of biomass (Houghton et al., 2009). The drying temperature of $40^{\circ} \mathrm{C}$ before lipid extraction with the hexane: methanol mixture increased the total lipid content relative to 60 and $90^{\circ} \mathrm{C}$. These results show a rapid decrease in the content of lipids with increasing drying temperature. As could be seen, crude oil was degraded. When lipids were expozed to higher temperature, oxidation occurred. According to Frankel (1993, 1998), oxidation is one of the most important reactions in lipid chemistry and this process depends on storage temperature and proceeds slowly at room temperature. However, temperature is one of the physical parameters that affect the rate of reaction. Therefore, the drying temperature had a significant impact on the biomass composition and lipid content $(p<0.05)$. In the chloroform: methanol extraction, no effect of the drying temperature on the crude oil content was observed. The dependency of the lipid content on the organic solvent and pretreatment is shown in Fig. 3.
Given its highest amount of total lipids, wet algal biomass was sonicated and treated by microwaves. Microwaves and sonication used as disruption techniques were efficient and yielded a higher amount of lipids compared to that obtained from the wet non-pretreated microalgal biomass. The results are shown in Table 4 . The influence of cell disintegration on lipid yield was significant $(p<0.05)$. Sonication uses cavitation waves induced by ultrasounds in the solution. This is related to the fact that the continuity of microalgal cell walls is disrupted. Microwaves induce an electromagnetic effect, which affects cell wall thickness and

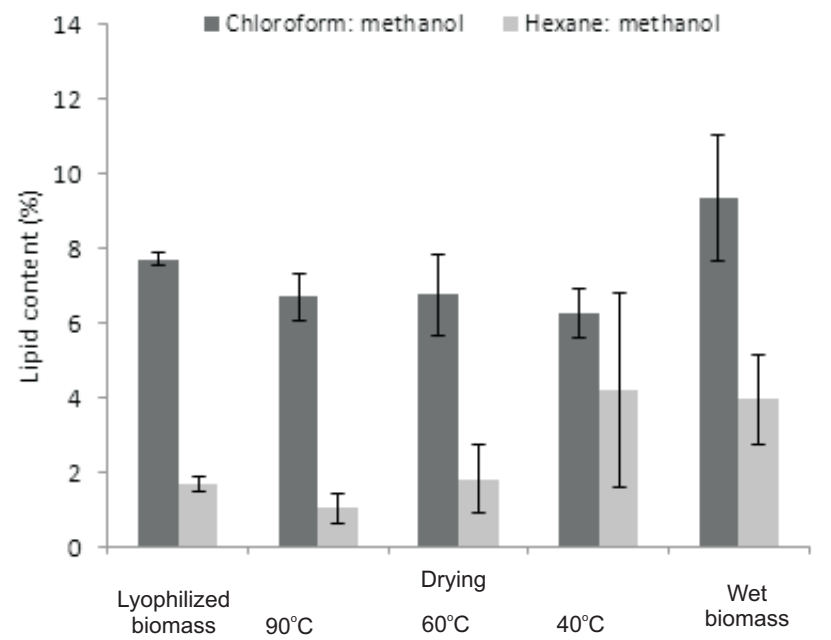

Fig. 3. Effect of the various mixtures of organic solvent and the type of pretreatment on the lipid content of Chlorella protothecoides.

T a b l e 4. Comparison of the lipid content in wet Chlorella protothecoides biomass with and without cell disruption methods

\begin{tabular}{lccc}
\hline \multirow{2}{*}{ Type of extraction } & \multicolumn{3}{c}{ Lipid content $(\% \mathrm{w} / \mathrm{w})$} \\
\cline { 2 - 4 } & Wet biomass & Wet biomass/microwave & Wet biomass/sonication \\
\hline Hexane: methanol & $3.94 \pm 1.19$ & $17.92 \pm 3.79$ & $41.43 \pm 12.37$ \\
Chloroform: methanol & $9.34 \pm 1.66$ & $21.39 \pm 11.52$ & $42.00 \pm 2.97$ \\
\hline
\end{tabular}




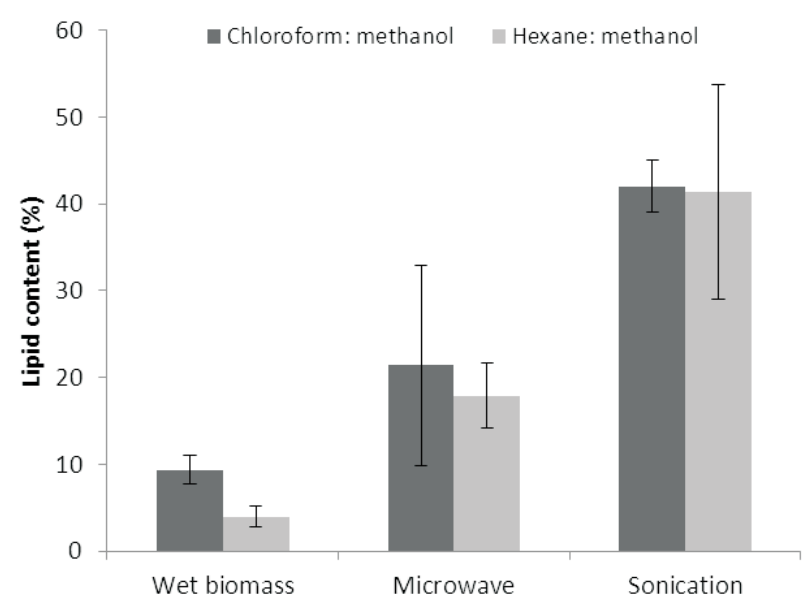

Fig. 4. Recovery rate of lipids from wet biomass and pretreated wet biomass. SD is given in bars.

destroys microalgal cells. Compared to the untreated samples in the chloroform:methanol extraction method, the lipid yield was increased in the sonication and microwaves approach by 32.67 and $12.05 \%$, respectively. In the hexane: methanol extraction, the lipid yield increased by about $37.48 \%$ for sonication and $13.97 \%$ for microwave. Both these cell disruption methods show considerable improvement in lipid extraction. This dependency is illustrated in Fig. 4. No decreasing amounts were detected. A similar result was reported by Prabakaran et al. (2011). They compared the effect of the cell disruption method on lipid extraction for three microalgal species (Chlorella sp., Nostoc sp. and Tolypothrix sp.) and observed the highest lipid content in the sonication method. Their study suggested that the sonication method was the most suitable for large-scale lipid extraction from microalgae. Furthermore, the microwave method was also efficient among the techniques that they used. It could be concluded from this result that the cell wall should be destroyed for efficient oil extraction. Also, Suganya and Renganathan (2012) reported that ultrasonic pretreatment improved lipid extraction more than microwave pretreatment. During extraction with cell disruption techniques, the choice of the solvent was not relevant. The influence of the solvent on lipid yield was not significant ( $>>0.05$ ). However, Halim et al. (2012b) suggested that the level of cell disruption during sonication could be species dependent. Both extraction methods were slightly more efficient after applying cell disruption techniques.
Figure 5 shows the composition and content of fatty acids in Chlorella protothecoides according to the extraction method and pretreatment. The type of the extraction method had a significant effect on palmitic acid, stearic acid, and oleic acid $(\mathrm{p}<0.05)$, and significant differences were detected in fatty acid profiles depending on the different kinds of pretreatment $(\mathrm{p}<0.05)$. The main fatty acids for the photoheterotrophic culture of Chlorella protothecoides were linoleic acid (C18:2), palmitic acid (C16:0), oleic acid (C18:1), linolenic acid (C18:3), and stearic acid (C18:0). These FAMEs represent more than $70 \%$ of the total acids. Among them, linoleic acid dominated in almost all the samples.

In the chloroform: methanol extraction, the lyophilized and dried $\left(90,60\right.$, and $\left.40^{\circ} \mathrm{C}\right)$ biomass had a higher content of oleic acid and a lower content of palmitic acid. In the wet biomass, the contents of oleic acid and palmitic acid were similar. In the hexane: methanol extraction, the proportions between $\mathrm{C} 16: 0, \mathrm{C} 18: 0$, and $\mathrm{C} 18: 1$ were changed. The content of palmitic acid was higher in all the samples. The results obtained in the hexane:methanol extraction were characterized by a large standard deviation. This makes this method not reliable.

It is worth noting that in the microwave-assisted method, the content of saturated fatty acids (C16:0 and C18:0) increased while the content of unsaturated fatty acids such as C18:1, C18:2, and C18:3 decreased. Especially, it is evident in the chloroform: methanol extraction. A similar result was obtained by Cheng et al. (2013). They argue that the electromagnetic effect and heat rapture unstable bonds in a carbon chain and change the structure. Microwave as a cell disruption technique improves extraction of crude oil, regardless of the influence on the fatty acid profile. Similar results were obtained in the sonication-assisted method of extraction. The content of saturated fatty acids increased while the yield of unsaturated fatty acids (C18:1 and C18:3) decreased. Based on previous considerations, the decline may result from breakdown of unstable bonds. Breaking of unstable bonds occurs as a result of the energy produced during sonication.

There is a clear trend that the highest $\mathrm{C} 18: 2$ content was observed for the microalgal photoheterotrophic culture of Chlorella protothecoides in this investigation. The profile of fatty acids of a microalgal species is known to be a function of cultivating and environmental conditions (Halim et al., 2011). Our research focused on a high biomass yield without unprofitable, stressful conditions. Yeh and Chang (2012) reported that photoheterotrophic growth of Chlorella vulgaris under favourable conditions results in high biomass production and a fatty acid composition rich in linoleic acid. 


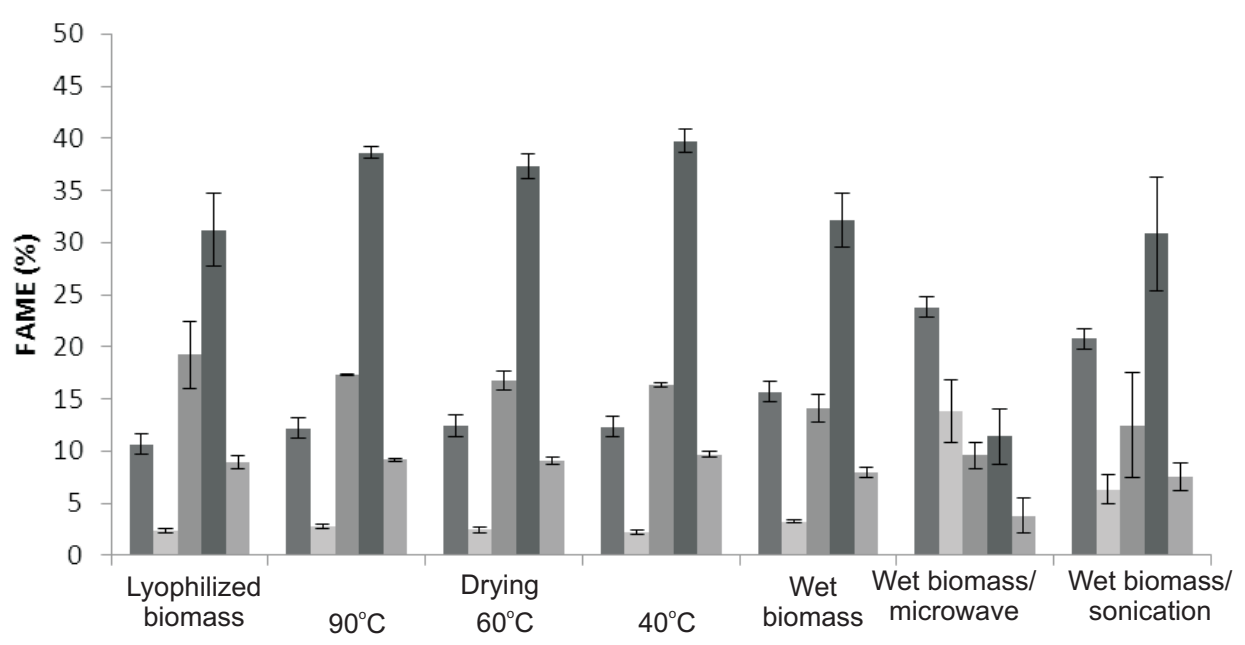

b

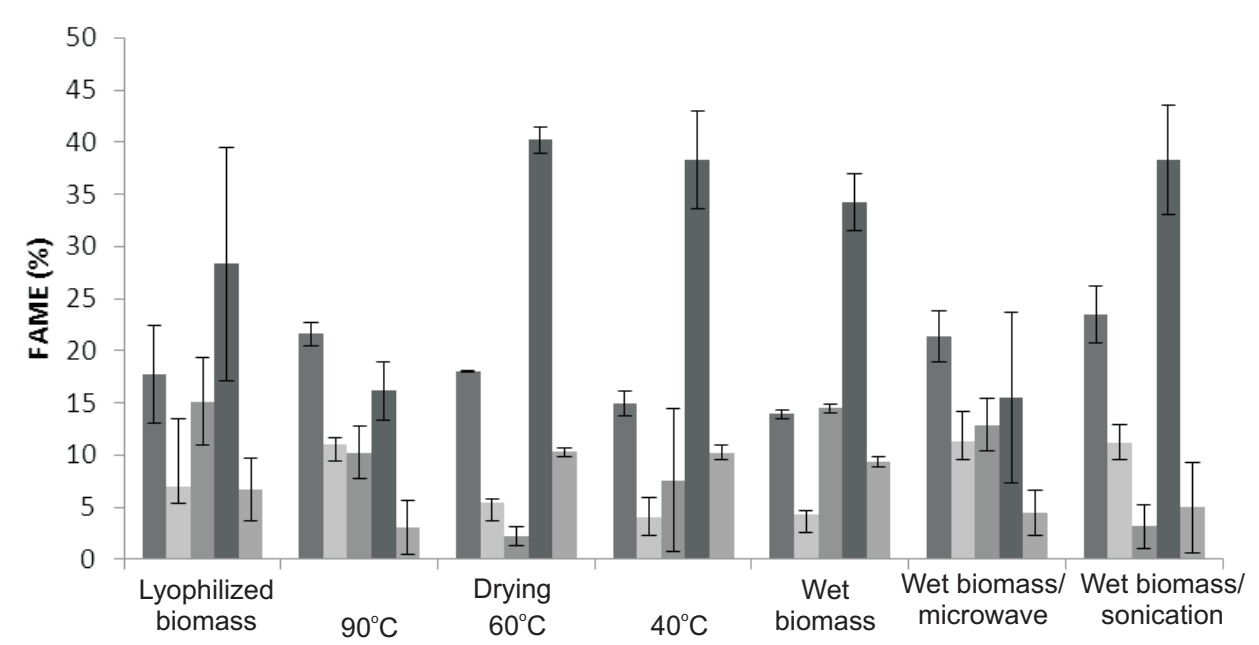

Fig. 5. Fatty acid methyl esters content and composition: $a$ - chloroform : methanol extraction, $b$ - hexane: methanol extraction.

\section{CONCLUSIONS}

1. The most appropriate solvents for lipid extraction from Chlorella protothecoides biomass was the chloroform: methanol mixture in the modified Bligh and Dyer method.

2. Wet biomass of Chlorella protothecoides was shown to produce the highest lipids yield $(9.34 \%)$ in the modified Bligh and Dyer extraction method.

3. Cell disruption methods improved the efficiency of lipid extraction. The ultrasonic pretreatment caused the highest increase in crude oil (42\%).

4. The ultrasonic and microwave pretreatment caused an increase in the palmitic acid content in the fatty acids profile. Both methods induced changes in the ratio of unsaturated to saturated fatty acids.

5. Lipid extraction from wet microalgal biomass after sonication is an alternative to the commonly used methods of lipid recovery.

\section{REFERENCES}

Ahmad A.L., Mat Yasin N.H., Derek C.J.C., and Lim J.K., 2011. Microalgae as a sustainable energy source for biodiesel production. A review. Renew Sust. Energ. Rev., 15, 584-593.

Barsanti L. and Gualtieri P., 2006. Algae-Anatomy, Biochemistry, and Biotechnology. CRC Press, Taylor Francis, Boca Raton, FL, USA.

Bligh E.G. and Dyer W.J., 1959. A rapid method of total lipid extraction and purification. Can. J. Biochem. Phys., 37, 911-917.

Cheng J., Sun J., Huang Y., Feng J., Zhou J., and Cen K., 2013. Dynamic microstructure and fractal characterization of cell wall disruption for microwave irradiation - assisted lipid extraction from wet microalgae. Biores. Technol., 150, 67-72.

Christie W.W., 1982. Lipid Analysis. Pergamon Press, Oxford, UK.

Chun-Zhao L., Sen Z., Ling X., Feng W., and Chen G., 2013. Algal oil extraction from wet biomass of Botryococcus braunii by 1,2-dimethoxyethane. Appl Energ., 102, 971-974. 
Demirbas M.F., Balat M., and Balat H., 2009. Potential contribution of biomass to the sustainable energy development. Energy Convers Manag., 50, 1746-1760.

Frankel E.N., 1993. In search of better methods to evaluate natural antioxidants and oxidative stability in food lipids. Trends Food Sci. Technol., 4, 220-225.

Frankel E.N., 1998. Lipid Oxidation. Oily Press, Dundee, UK.

Fu C.C., Hung T.C., Chen J.Y., Su C.H., and Wu W.T., 2010. Hydrolysis of microalgae cell walls for producing of reducting sugar and lipid extraction. Biores. Technol., 100, $8750-8754$.

Goschina I.A. and Harwood J.L., 2006. Lipids and lipid metabolism in eukaryotic algae. Prog. Lipid Res., 45, 160-186.

Guy A. and Thompson G.A. Jr., 1996. Lipids and membrane function in green algae. Review. Biochim. Biophys. Acta, $1302,17-45$.

Halim R., Danquah M.K., and Webley P.A., 2012a. Extraction of oil form microalgae for biodiesel production: a Review. Biotechnol. Adv., 30, 709-732.

Halim R., Harun R., Danquah M.K., and Webley P.A., 2012 b. Microalgal cell disruption for biofuel development. Appl. Energ., 91, 116-121.

Halim R., Gladman B., Danquah M.K., and Webley P.A., 2011. Oil extraction from microalgae for biodiesel production. Biores. Technol., 102, 178-185.

Houghton T.P., Stevens D.M., Pryfogle P.A., Wright C.T., and Radtke C.W., 2009. The effect of drying temperature on the composition of biomass. Appl. Biochem. Biotechnol., 153, 4-10.

International Energy Agency, 2012. World Energy Outlook. International Energy Agency, Paris, France.

Isleten-Hosoglu M., Ayyildiz-Tamis D., Zengin G., and Elibol M., 2013. Enhanced growth and lipid accumulation by a new Ettlia texensis isolate under optimized photohetertrophic condition. Biores Technol., 131, 258-265.

Iverson S.J., Lang S.L.C., and Cooper M.H., 2001. Comparison of the Bligh and Dyer And Folch methods for total lipid determination in a broad range of marine tissue. Lipids, 36(11), 1283-1287.

Kachel-Jakubowska M. and Szpryngiel M., 2008. Influence on drying condition on quality properties of rapeseed. Int. Agrophysics, 22, 327-331.

Kates M., 1986a. Definision and clasification of lipds.Techniques of lipidology: isolation, analysis and identification of lipids. In: Laboratory Techniques in Biochemistry and Molecular Biology (Eds R.H. Burdon, P.H. Knippenberg). Elsevier Press, New York, USA.

Kates M., 1986b. Lipid extraction procedures. Techniques of lipidology: isolation, analysis and identification of lipids. In: Laboratory Techniques in Biochemistry and Molecular
Biology (Eds R.H. Burdon, P.H. Knippenberg). Elsevier, New York, USA.

Krzemińska I., Pawlik-Skowrońska B., Trzcińska M., and Tys J., 2014. Influence of photoperiods on the growth rate and biomass productivity of green microalgae. Bioprocess Biosyst. Eng., 37(4), 735-741.

Pomeranz Y. and Meloan C.L., 1994. Food Analysis.Theory and Practice. Westport, CT, USA.

Prabakaran P. and Ravindran A.D., 2011. A comparative study on effective cell disruption methods for lipid extrac-tion from microalgae. Lett. Appl. Microbiol., 53(2), 150-154.

Qiang H., Sommerfeld M., Jarvis E., Ghirardi M., Posewitz M., Seibert M., and Darzins A., 2008. Microalgal triacyloglicerols as feedstock for biofuel production: perspectives and advances. Plant J., 54, 621-639.

Robles Medina A., Molina Grima E., Giménez Giménez A., and Ibanez González M.J., 1998. Downstream processing of algal polyunsaturated fatty acids. Biotechnol. Adv., 16(3), 517-580

Ryckebosch E., Muylaert K., and Foubert I., 2012. Optimization of an analytical procedure for extraction of lipids from microalgae. J. Am. Oil Chem. Soc., 89(2), 189-198.

Sathish A. and Sims R.C., 2012. Biodiesel from mixed culture alga via a wet lipid extraction procedure, Biores. Technol., 118, 643-647.

Shahidi F. and Wanasundara P.K.J.P.D., 2002. Extraction and analysis of lipids. In: Food Lipids - Chemistry, Nutrition, and Biotechnology (Eds C.C. Akoh, D.B. Min). Dekker Press, New York, USA.

Suganya T. and Renganathan S., 2012. Optimalization and kinetic studies on algal oil extraction from Marine macroalgae Ulva lactuca. Biores. Technol., 107, 319-326.

Tanzi C.D., Vian M.A., and Chemat F., 2013. New procedure for extraction of algal lipids from wet biomass: A Green clean and scalable process. Biores. Technol., 134, 271-275.

Widjaja A., Chien C.C., and Ju Y.H., 2009. Study of increasing lipid production from fresh water microalgae Chlorella vulgaris. J. Taiwan Inst. Chem., 40, 13-20.

Xiong W., Li X., Xiang J., and Wu Q., 2008. High-density fermentation of microalga Chlorella protothecoides in bioreactor for microbio-diesel production. Appl. Microbiol. Biotech., 78(1), 29-36.

Yadavalli R., Rao C.S., Reddy D.C., Sivasai K.S.R., and Rao S.R., 2010. Effect of different culture media on cell concentrations of Chlorella pyrenoidosa under photoautotrophic conditions. Int. J. Natural Eng. Sci., 4(3), 47-51.

Yeh K.L. and Chang J.S., 2012. Effects of cultivation conditions nad media composition on cell growth and lipid productivity of indigenous micro alga Chlorella vulgaris ESP-31. Biores. Technol., 105, 120-127. 